\title{
Treatment of Chronic Spontaneous Urticaria
}

\author{
Allen P. Kaplan* \\ Department of Medicine, Division of Pulmonary and Critical Care Medicine, Allergy and Clinical Immunology, Medical University of South Carolina, Charleston, \\ SC, USA
}

This is an Open Access article distributed under the terms of the Creative Commons Attribution Non-Commercial License (http://creativecommons.org/licenses/by-nc/3.0/) which permits unrestricted non-commercial use, distribution, and reproduction in any medium, provided the original work is properly cited.

Chronic spontaneous urticaria is defined as persistent symptoms of urticaria for 6 weeks or more. It is associated with autoimmunity in approximately 45 percent of patients. Therapy is often difficult however the initial approach should employ high-dose non-sedating antihistamines; 4-6 tablets/day may be necessary. It has been shown that the response to 4 tablets/day exceeds 3 , and exceeds 2 , which exceeds 1 . However the dose that corresponds to the maximal dose of first generation antihistamines (hydroxyzine, diphenhydramine) used previously, is 6/day. Yet over half the patients are refractory to antihistamines and other agents should be tried next. Whereas current guidelines (published) often add leukotriene antagonists and/or $\mathrm{H}_{2}$ receptor antogonists next, these are of little utility. Likewise drugs effective for urticarial vasculitis (colchicine, dapsone, sulfasalazine, hydroxychloroquine) are effective in a small percentage of patients and no study suggests that the response rate of any of them exceeds the $30 \%$ placebo responses seen in most double-blind, placebo controlled studies. The drugs that are effective for antihistamine-resistant chronic spontaneous urticaria are corticosteroids, cyclosporine, and Omalizumab. Use of steroids is limited by toxicity. If used at all, a dose of no more than $10 \mathrm{mg} /$ day should be employed with a weekly reduction of $1 \mathrm{mg}$. The response rates to cyclosporine and Omalizumab are each close to $75 \%$. Cyclosporine can be used effectively if care is taken to monitor blood pressure, urine protein, blood urea nitrogen, and creatinine, every 6 weeks. Omalizumab has the best profile in terms of efficacy/toxicity and, once approved by federal agencies for use in chronic spontaneous urticaria, a dramatic change in the treatment paradigm, whether associated with autoimmunity or not, is predicted. A phase 3 trial is currently in place. Refractoriness to both Omalizumab and cyclosporine is expected to be less than 5 percent of patients. Other agents, can then be tried.

Key Words: Urticaria; anti lgE receptor; antihistamine; cyclosporine; omalizumab

\section{INTRODUCTION}

Urticaria is considered "chronic" when there is persistence of symptoms for over 6 weeks. However, terminology has evolved during the past decade and has become more specific. Early on, the physical urticarias were included within the rubric of "chronic" even though they are really intermittent and dependent on an encounter with some external stimulus. The term chronic "idiopathic" urticaria was also employed for decades, however we know a lot more about the etiology and pathogenesis of chronic urticaria, although experiments that "prove" a particular mechanism have not yet been achieved. Also there remains a large subpopulation of patients whose hives remain an enigma and can still be considered to be of unknown origin i.e. idiopathic. More recently, the term chronic spontaneous urticaria has been employed ${ }^{1}$ to indicate chronic urticaria that is endogenous, and independent of any external physical stimulus, which is conceptually helpful, and does not imply knowing or not-knowing the cause. There is a clear association of a subpopulation of such patients ( $40 \%-45 \%)$ with autoimmunity who are generally more severe, and therefore more difficult to treat. ${ }^{2}$ Considerable pathogenic information is available and the term chronic autoimmune urticaria is often used by those of us who interpret the data as being causative or at least contributory in a substantial way. The non-autoimmune remaining $55 \%-60 \%$ of patients might still be considered to be idiopathic in that we have very little insight as to the cause or the pathogenesis. All these are "spontaneous".

\section{PATHOGENESIS}

The key observations leading to an autoimmune designation

Correspondence to: Allen P. Kaplan, MD, Department of Medicine, Division of Pulmonary and Critical Care Medicine, Allergy and Clinical Immunology, Medical University of South Carolina, 171 Ashley Avenue, Charleston, SC 29425, USA.

Tel: +1-843-729-0264; Fax: +1-843-722-1253; E-mail: kaplana@musc.edu Received: February 22, 2012; Accepted: March 20, 2012

- There are no financial or other issues that might lead to conflict of interest. 
for many patients with chronic spontaneous urticarial have been recently reviewed in considerable detail ${ }^{2}$ and will be summarized only briefly herein. Patients were found to be autoreactive to their own serum, ${ }^{3}$ now employed as the autologous skin test. ${ }^{4}$ Although both sensitivity and specificity of this test is limited, most patients who react to their own serum to produce a wheal and flare reaction upon intradermal skin test, are responding to an IgG immunoglobulin with a positive incidence of about $30 \%$. Soon thereafter, reports appeared indicting that an occasional patient (5\%-10\%) has circulating IgG anti-IgE that is functional and can activate donor basophils to release histamine. ${ }^{5,6} \mathrm{Next}$, a much larger number of patients were found to have IgG antibody directed to the IgE receptor $\alpha$ subunit. ${ }^{7}$ This autoantibody was functional on skin mast cells and basophils ${ }^{8,9}$ and can be an initiating stimulus for hive formation. It is important to note that the IgG of many such patients was purified and shown to possess this reactivity, ${ }^{9}$ even though most routine assays employ whole serum with no further molecular characterization. Saturating IgE receptors with myeloma IgE blocked the ability of patients' anti receptor antibody to degranulate basophils, ${ }^{10}$ and the histamine release was augmented by serum complement. ${ }^{11}$ This was subsequently shown to be due to activation of the classical complement pathway and the augmentation was eliminated by employing C5-deficient serum added to purified patient $\mathrm{IgG}^{12}$ or by adding antibody to the C5a receptor to patients' sera prior to assay. Thus considerable molecular evidence exists regarding the function of these autoantibodies. When histamine release is employed as the assay, positive tests rarely occur in normal subjects, or in other urticarial disorders, or in autoimmune disorders. In one assay we reported 54 positives in 104 patients with chronic spontaneous urticarial and none in 35 allergic patients lacking urticaria. ${ }^{13}$

It is important to note that binding assays (enzyme-linked immunosorbent assay [ELISA], immunoblot) for anti IgE receptor antibodies employing cloned $\alpha$ subunit give false positives and likely accounts for the non-specificity reported. ${ }^{14}$ In one of the original reports of positive antibodies to the IgE receptor in patients with autoimmune diseases such as pemphigus and dermatomyositis, the authors were unable to demonstrate any histamine release even though positive ELISA assays or positive immunoblots were observed. ${ }^{15}$ Histamine release was observed only in the patients who had chronic urticaria. Other published reports are similar. ${ }^{16,17}$ When we attempted to develop an ELISA binding assay to substitute for basophil histamine release, we failed because positives were found in virtually everyone ${ }^{18}$ even when the assay was made specific to $\operatorname{IgG}_{1}$ and $\mathrm{IgG}_{3}$ subclasses. The latter subclasses are the major ones that fix complement and account for most of the histamine-releasing activity. ${ }^{19} \mathrm{In}$ fact $\operatorname{IgG}_{2}$ antibodies to the IgE receptor $\alpha$ subunit were found by binding assay and not by histamine release in patients whose $\mathrm{IgG}_{1}$ and/or IgG $\mathrm{I}_{3}$ clearly caused histamine secretion. ${ }^{19}$ This is consistent with recent observations that the non-specific reac- tivity is due to antibody binding to the insect carbohydrate attached to the human $\alpha$ subunit since it was originally cloned employing an insect vector. ${ }^{20}$ Such binding does not lead to IgE receptor perturbation requisite for histamine release.

Additional observations regarding pathogenesis include decreased responsiveness of patients basophils to rodent anti IgE due to elevated phosphatases, ${ }^{21}$ activation of the extrinsic coagulation cascade based on the presence of activated Factor VII, thrombin fragments, and fibrin split products, ${ }^{22,23}$ as well as elevated levels of metalloproteinase $9^{24}$ and vascular endothelial cell growth factor. The relation to disease pathogenesis is unclear although the aforementioned basophil abnormality reverses upon urticaria-remission or successful therapy. ${ }^{25}$

\section{TREATMENT}

Numerous guidelines are available ${ }^{1,26,27}$ to assist physicians in treating patients with chronic spontaneous urticaria. The mainstay of initial therapy is clearly high-dose antihistamines and patients can be divided into those that are antihistamine responsive and those who are not. The number of alternatives to antihistamines is large but the evidence of efficacy for most of them is weak. On the other hand, some of the new approaches are extremely effective and have the potential to radically change the approach to treating this often frustrating disorder.

\section{Antihistamine responsive patients}

Antihistamines are effective in treating $45 \%-60 \%$ of patients; the remainder are refractory and achieve little or no benefit even from maximal doses. This is not surprising because chronic spontaneous urticaria should not be viewed as a disorder mediated by histamine secretion any more than rhinitis or asthma are histamine mediated. Clearly histamine is a major contributor, but allergic or allergic-like disorders characterized by a prominent cellular infiltrate (either a late-phase reaction or comparable inflammatory response) often require additional approaches. The frequent requirement for corticosteroids to treat allergic rhinitis or asthma is a testament to that proposition, and the cellular infiltrate that characterizes chronic urticaria $^{28-30}$ (a non-necrotizing perivascular infiltration of CD4+ lymphocytes, monocytes, neutrophils, eosinophils, and basophils) falls into that category. By contrast, dermatographism is an example of a histamine-mediated urticaria i.e. we know of no other mediator, there is no significant cellular infiltrate, and no evident late-phase reaction once the wheal and flare reaction subsides. It responds to antihistamines but not to steroid.

Responsiveness to antihistamines is dependent on occupancy of $\mathrm{H}-1$ receptors. These drugs are inverse agonists that lock the $\mathrm{H}-1$ receptor into an inactive conformation. Histamine shifts the receptor equilibrium to an active conformation leading to vasodilatation and increased vascular permeability. Thus although antihistamines do not complete with histamine for 
binding to the $\mathrm{H}-1$ receptor, as would a competitive antagonist, they do compete regarding the receptor conformation equilibrium. Thus, histamine released into the skin can lead to histamine-induced receptor effects even in the face of antihistamine therapy when the antihistamine receptor occupancy, based on the dose taken, is too low. The antihistamine will then be ineffective. That is the reason why the typical once-a-day second generation "non-sedating" antihistamine used to treat allergic rhinitis often fail to be effective in the treatment of chronic urticaria. The fact that innumerable studies of these drugs show that one/day is better than placebo, ${ }^{31-35}$ although true, is misleading because the benefit accrued, but for the mildest of patients, is too low to be of significance in terms of patient symptom relief or quality of life when the disease is moderate to severe.

This became apparent recently with the study of cold urticaria, ${ }^{36}$ a predominantly histamine-mediated urticaria, where 4 tablets per day was more effective than 3 tablets per day which was more beneficial than 2 or 1 tablet per day. This comes as no surprise although it was presented as conceptually new. The prior drug of choice was cyprohaptadine, ${ }^{37}$ a first generation antihistamine that is dispensed as $4 \mathrm{mg}$ tablets and 4-8 tablets/ day was required to treat most cold urticarial patients. ${ }^{38}$ Although chronic spontaneous urticarial has a lesser response to antihistamine and is a far more complex disorder, the same scenario of 4 tablets/day being better than lesser quantities ${ }^{39}$ was found. This too, is not new. For example, 4 cetirizines/day is equal to $25 \mathrm{mg}$ of hydroxyzine taken 5 tablets/day and the dose of hydroxyzine found to be effective for chronic urticaria patients varied from 100-200 mg/day ${ }^{40}$ in divided doses. Although not tested in a blinded or placebo controlled fashion, the same increasing responsiveness (in those responsive to antihistamines at all) was noted, and the patient number exceeded 10,000 over 35 years. ${ }^{41}$ By this analysis, a dose of 6 cetirizines/day would be predicted to be maximal for the most severe, but still responsive patients.

The choice of antihistamine to be used favors the second generation agents which have been studied to a much greater extent than first-generation agents and are more specific for the H-1 receptor and have a better side-effect profilé. ${ }^{42}$ For example they have less sedation, and less likely to cause dry mouth, do not cross the blood-brain barrier to any appreciable extent (fexofenadine may be the only one that is truly zero), do not effect REM sleep, etc. ${ }^{43}$ Thus it is assumed that long-term therapy with first generation agents, even if equally effective as second-generation agents for treatment of chronic spontaneous urticaria, would lead to poor performance at work or at school, auto accidents, etc.

Although first generation agents were used successfully for decades before second-generation agents became available, guidelines emphasizing use of second-generation agents as a routine now, seems appropriate. ${ }^{1}$ However data demonstrating harmful side effects when first-generation agents are used chronically in patients with chronic spontaneous urticaria do not exist i.e. the conclusion may be correct but the reasons given, may be incorrect or at least substantially exaggerated. My opinion, previously published ${ }^{41}$ is based on extensive experience employing first generation agents with therapeutic success and very few side effects. The issue is that side effects of first-generation agents has not been assessed in chronic urticaria patients, but extrapolated based on what has been observed in normal subjects or those with other allergies. Second, the duration of such studies is relatively short i.e. usually a few days, and often just one or two doses of an antihistamine such as diphenhydramine is reported. But if side-effects are most prominent in the first few days and dissipate over a week, could they not be employed if the duration of therapy varies from 3 months to 2 years? Is there CNS tachyphylaxis over time (which requires crossing the blood-brain barrier)? Is the non-specificity of first-generation antihistamines helpful because of some of the additional receptor-mediated effects? These questions can be answered only by a direct comparison of high-dose therapy in patients with chronic urticaria employing closely related agents such as cetirizine vs. hydroxyzine each of which is known to be efficacious.

\section{Antihistamine refractory patients}

High dose antihistaminics (H1 receptor "antagonists") are effective in $45 \%-50 \%$ of patients and no other therapy is required other than tapering the dose as the patient improves. However refractory patients require addition or substitution of alternative agents. These are listed in Table; the left side includes those that are in the literature and are included in most guidelines while the right side lists only 4 (3, not including antihistamines) which are the only ones that I believe to be efficacious in a large percentage of histamine-refractory patients.

The newest and most promising approach to the treatment of refractory patients is the use of Omalizumab. A phase one trial,

Table. Therapeutic choices

\begin{tabular}{ll}
\hline Antihistamines & Antihistamines \\
First \& Second Generation & First \& Second Generation \\
$\mathrm{H}_{2}$-receptor antagonists & Corticosteroid \\
Leucotriene antagonists & Cyclosporine \\
Hydroxychloroquine & Omalizumab \\
Dapsone & \\
Colchicine & \\
Sulfasalazine & \\
Cyclosporine & \\
Omalizumab &
\end{tabular}

Choices of therapies for treatment of chronic spontaneous urticaria. The column on the left lists most drugs commonly employed. The list on the right includes only those agents to which most patients respond. The response rate to antihistamines is $45 \%-50 \%$ and the response to corticosteroid (low-dose), Omalizumab, and cyclosporine are each about 70\%-80\%. 

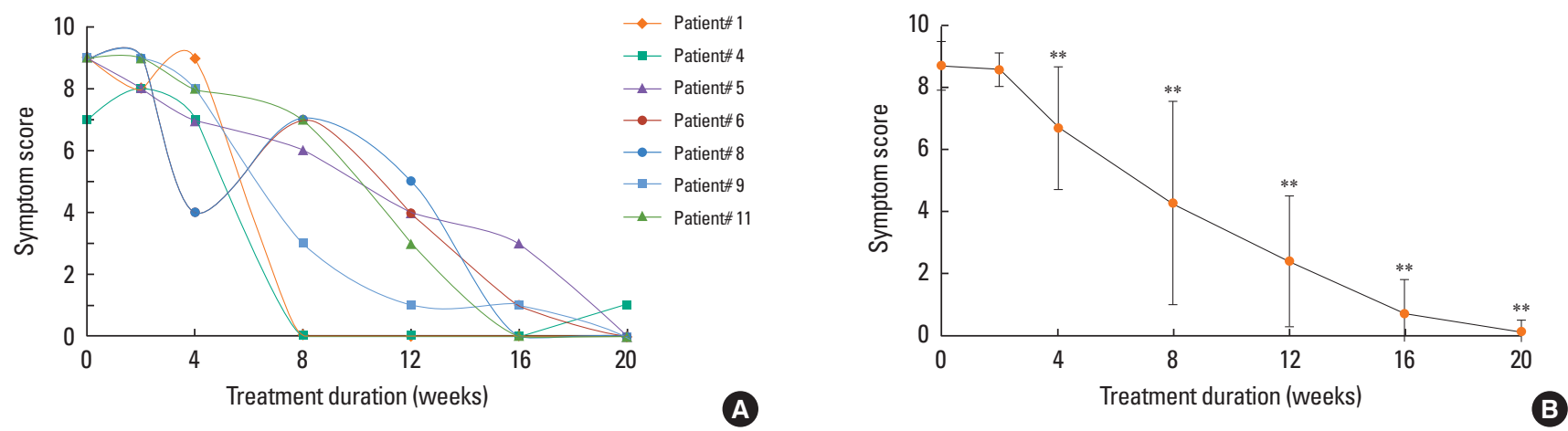

Figure. (A) Response of 7 patients to Omalizumab demonstrating progressive relief of symptoms, all of whom remit between 1 month and 4 months of a monthly injection. In this study, 4 additional patients improved, but did not remit, and one did not respond. (B) Composite symptom score for patients showing the mean and standard error at each time point. A significant difference is noted by 4 weeks.

single blinded, and placebo controlled revealed a success rate in 11 of 12 patients with 7 of them achieving remission. ${ }^{44}$ The data are shown individually in Figure. A phase 2 trial included 80 patients and revealed the same result with a response rate of over $75 \%$ many of whom improved dramatically. ${ }^{45}$ The former study chose particularly severe patients with chronic autoimmune urticaria. All had IgG anti IgE receptor antibodies and many also had antithyroid antibodies. The latter study employed patients with chronic spontaneous urticaria; the presence or absence of autoimmunity was not assessed. Many other case reports attest to the efficacy of Omalizumab ${ }^{46-49}$ and one study employed patients without autoimmunity with virtually the same response rate. ${ }^{50}$ Two aspects of these studies indicate that IgE anti receptor antibody is not necessarily a cause of chronic urticaria, even in a subpopulation of patients. The response in those lacking autoantibodies is unexplained, while the response in those with IgG anti IgE receptor antibody is often so rapid that time sufficient for downregulation of the IgE receptor (as IgE levels plummet) has not transpired. A non-specific, rapidly occurring down-regulation of mast cell secretion is suggested.

Cyclosporine has been shown to be effective in the therapy of severe chronic urticaria unresponsive to other modalities in two double blind, placebo-controlled trials. ${ }^{51,52}$ Experience has substantiated these optimistic results with a response rate of 75\%$80 \%$. The average dose for an adult is $200 \mathrm{mg} /$ day $(3-3.5 \mathrm{mg} / \mathrm{kg}$ ); occasional patients may require $250 \mathrm{mg}$ or even $300 \mathrm{mg}$ but we have never exceeded this dose. After a few quiescent months, it can be tapered at $50 \mathrm{mg} / \mathrm{month}$ down to $100 \mathrm{mg} /$ day and then $25 \mathrm{mg} / \mathrm{month}$. Cyclosporine has side effects that require monitoring including effects on blood pressure and renal function. We suggest a blood urea nitrogen, creatinine, urinalysis, and blood pressure check at the start of therapy and every 4-6 weeks thereafter. Thus it is contraindicated in patients with hypertension or renal dysfunction but can be employed in diabetics who have normal renal function where steroids would be contraindicated.

The most common drug used to treat severe chronic sponta- neous urticaria is corticosteroid. Unfortunately high doses are commonly employed for protracted periods of time. Although there are no recent studies of efficacy, there is no question that patients respond. However guidelines recommend short term use for acute urticarial episodes, but do not recommend sustained use because of the risk of side effects including weight gain, hypertension, osteoporosis, cutaneous striae, cataracts, and altered fat distribution. There is no question that chronic, high-dose steroids should not be used to treat chronic urticaria. However in precluding sustained use, one potentially effective approach has been eliminated. Prior to the advocacy of cyclosporine or Omalizumab, we recommended alternate day steroid at 20-25 mg every other day which averages $10-12.5 \mathrm{mg}$ each day and more recently, favor daily use starting at $10 \mathrm{mg} /$ day. If a daily approach is employed, a considerable lessening in symptoms often is seen and the dose can be tapered at $1 \mathrm{mg} /$ week. This is an effective, safe approach so that the duration of steroid use averages about 3 months, with the dosage gradually decreasing. When steroids were originally employed for autoimmune diseases such as rheumatoid arthritis, high daily doses were employed, and side effects were considerable. Their utility was questioned because long-term side effects exceeded any benefit. However low-dose steroid treatment was later employed with much greater utility. Even now when methotrexate plus potent biologic agents are employed, steroids have been found to be effective at the $5-10 \mathrm{mg} /$ day range $\mathrm{e}^{53}$ and can be used for years with severe side-effects averted even though rheumatoid arthritis is associated with periarticular osteoporosis. There is no reason why we cannot use corticosteroids in a rational way for chronic spontaneous urticaria. At present, Omalizumab is not approved by the FDA in the USA for use in chronic urticaria and the situation worldwide is likely similar. If a histamine refractory patient cannot take cyclosporine, the agent with the greatest response rate is low-dose corticosteroid.

The list on the left side of Table includes $\mathrm{H}_{2}$ receptor antagonists and leukotriene antagonists. The literature regarding these agents is of dubious quality, involving relatively small numbers 
of patients, and they are more often prescribed as additives to $\mathrm{H}-1$ receptor antagonists, than used individually. Experience with them has been generally disappointing. If the patient is unresponsive to high-dose $\mathrm{H}-1$ antihistamines, adding these is unlikely to create a responsive individual. Other agents such as dapsone, colchicine, and hydroxychloroquine were originally suggested for urticarial vasculitis, a totally different disorder from chronic spontaneous urticaria, so that reasoning that an effect on one will necessarily lead to a positive response in the other is erroneous. Actual studies of these drugs are limited so that there is little convincing evidence that they work. None of these drugs have been studied in a double bind placebo-controlled fashion in a large enough group of patients with a response rate that exceeds the $30 \%-35 \%$ response to placebo. None of these achieve that level of response. Sulfasalazine is favored by some since it is effective in some arthritics and is a major agent for ulcerative colitis where 5 amino-salicylic acid is the active moiety. The best study of this agent lacks a control group $^{54}$ and I am reluctant to treat hives with a sulfa compound and an aspirin derivative.

\section{SUMMARY}

The reliable drugs for the treatment of chronic spontaneous urticarial are antihistamines, Omalizumab, cyclosporine, and low-dose corticosteroids. With these agents, only a rare patient remains refractory and avoidance of the other agents listed in Table saves considerable time, cost, and frustration.

\section{REFERENCES}

1. Zuberbier T, Asero R, Bindslev-Jensen C, Walter Canonica G, Church MK, Giménez-Arnau AM, Grattan CE, Kapp A, Maurer M, Merk HF, Rogala B, Saini S, Sánchez-Borges M, Schmid-Grendelmeier P, Schünemann H, Staubach P, Vena GA, Wedi B; Dermatology Section of the European Academy of Allergology and Clinical Immunology; Global Allergy and Asthma European Network; European Dermatology Forum; World Allergy Organization. EAACI/GA(2) LEN/EDF/WAO guideline: management of urticaria. Allergy 2009; 64:1427-43.

2. Kaplan AP, Greaves M. Pathogenesis of chronic urticaria. Clin Exp Allergy 2009;39:777-87.

3. Grattan CE, Wallington TB, Warin RP, Kennedy CT, Bradfield JW. A serological mediator in chronic idiopathic urticaria--a clinical, immunological and histological evaluation. Br J Dermatol 1986;114: 583-90.

4. Grattan CE, Boon AP, Eady RA, Winkelmann RK. The pathology of the autologous serum skin test response in chronic urticaria resembles IgE-mediated late-phase reactions. Int Arch Allergy Appl Immunol 1990;93:198-204.

5. Gruber BL, Baeza ML, Marchese MJ, Agnello V, Kaplan AP. Prevalence and functional role of anti-IgE autoantibodies in urticarial syndromes. J Invest Dermatol 1988;90:213-7.

6. Grattan CE, Francis DM, Hide M, Greaves MW. Detection of circulating histamine releasing autoantibodies with functional properties of anti-IgE in chronic urticaria. Clin Exp Allergy 1991;21:695-704.

7. Hide M, Francis DM, Grattan CE, Hakimi J, Kochan JP, Greaves MW. Autoantibodies against the high-affinity IgE receptor as a cause of histamine release in chronic urticaria. N Engl J Med 1993; 328:1599-604.

8. Niimi N, Francis DM, Kermani F, O'Donnell BF, Hide M, KobzaBlack A, Winkelmann RK, Greaves MW, Barr RM. Dermal mast cell activation by autoantibodies against the high affinity IgE receptor in chronic urticaria. J Invest Dermatol 1996;106:1001-6.

9. Kikuchi Y, Kaplan AP. Mechanisms of autoimmune activation of basophils in chronic urticaria. J Allergy Clin Immunol 2001;107: 1056-62.

10. Kaplan AP. Chronic urticaria: pathogenesis and treatment. J Allergy Clin Immunol 2004;114:465-74.

11. Ferrer M, Nakazawa K, Kaplan AP. Complement dependence of histamine release in chronic urticaria. J Allergy Clin Immunol 1999; 104:169-72.

12. Kikuchi Y, Kaplan AP. A role for C5a in augmenting IgG-dependent histamine release from basophils in chronic urticaria. J Allergy Clin Immunol 2002;109:114-8.

13. Kaplan AP, Joseph K. Basophil secretion in chronic urticaria: autoantibody-dependent or not? J Allergy Clin Immunol 2007;120:72930 .

14. Hancock K, Narang S, Pattabhi S, Yushak ML, Khan A, Lin SC, Plemons R, Betenbaugh MJ, Tsang VC. False positive reactivity of recombinant, diagnostic, glycoproteins produced in High Five insect cells: effect of glycosylation. J Immunol Methods 2008;330:130-6.

15. Fiebiger E, Hammerschmid F, Stingl G, Maurer D. Anti-FcepsilonRIalpha autoantibodies in autoimmune-mediated disorders. Identification of a structure-function relationship. J Clin Invest 1998;101: 243-51.

16. Du Toit G, Prescott R, Lawrence P, Johar A, Brown G, Weinberg EG, Motala C, Potter PC. Autoantibodies to the high-affinity IgE receptor in children with chronic urticaria. Ann Allergy Asthma Immunol 2006;96:341-4.

17. Altrich ML, Halsey JF, Altman LC. Comparison of the in vivo autologous skin test with in vitro diagnostic tests for diagnosis of chronic autoimmune urticaria. Allergy Asthma Proc 2009;30:28-34.

18. Ferrer M, Kinét JP, Kaplan AP. Comparative studies of functional and binding assays for IgG anti-Fc(epsilon)RIalpha (alpha-subunit) in chronic urticaria. J Allergy Clin Immunol 1998;101:672-6.

19. Soundararajan S, Kikuchi Y, Joseph K, Kaplan AP. Functional assessment of pathogenic IgG subclasses in chronic autoimmune urticaria. J Allergy Clin Immunol 2005;115:815-21.

20. Ling M, Ge J, Altrich ML, Halsey JF. Importance of antigen selection in the detection of autoantibodies against FcERI $\alpha$ in chronic urticaria patients [abstract]. J Allergy Clin Immunol 2010;125 Suppl 1:AB30. Abstract no. 118.

21. Vonakis BM, Vasagar K, Gibbons SP Jr, Gober L, Sterba PM, Chang H, Saini SS. Basophil FcepsilonRI histamine release parallels expression of Src-homology 2-containing inositol phosphatases in chronic idiopathic urticaria. J Allergy Clin Immunol 2007;119:441-8.

22. Asero R, Tedeschi A, Coppola R, Griffini S, Paparella P, Riboldi P, Marzano AV, Fanoni D, Cugno M. Activation of the tissue factor pathway of blood coagulation in patients with chronic urticaria. J Allergy Clin Immunol 2007;119:705-10.

23. Asero R, Tedeschi A, Riboldi P, Griffini S, Bonanni E, Cugno M. Severe chronic urticaria is associated with elevated plasma levels of D-dimer. Allergy 2008;63:176-80. 
24. Kessel A, Bishara R, Amital A, Bamberger E, Sabo E, Grushko G, Toubi E. Increased plasma levels of matrix metalloproteinase- 9 are associated with the severity of chronic urticaria. Clin Exp Allergy 2005;35:221-5.

25. Eckman JA, Hamilton RG, Gober LM, Sterba PM, Saini SS. Basophil phenotypes in chronic idiopathic urticaria in relation to disease activity and autoantibodies. J Invest Dermatol 2008;128:195663.

26. Powell RJ, Du Toit GL, Siddique N, Leech SC, Dixon TA, Clark AT, Mirakian R, Walker SM, Huber PA, Nasser SM; British Society for Allergy and Clinical Immunology (BSACI). BSACI guidelines for the management of chronic urticaria and angio-oedema. Clin Exp Allergy 2007;37:631-50.

27. Grattan CE, Humphreys F; British Association of Dermatologists Therapy Guidelines and Audit Subcommittee. Guidelines for evaluation and management of urticaria in adults and children. Br J Dermatol 2007;157:1116-23.

28. Natbony SF, Phillips ME, Elias JM, Godfrey HP, Kaplan AP. Histologic studies of chronic idiopathic urticaria. J Allergy Clin Immunol 1983;71:177-83.

29. Elias J, Boss E, Kaplan AP. Studies of the cellular infiltrate of chronic idiopathic urticaria: prominence of T-lymphocytes, monocytes, and mast cells. J Allergy Clin Immunol 1986;78:914-8.

30. Sabroe RA, Poon E, Orchard GE, Lane D, Francis DM, Barr RM, Black MM, Black AK, Greaves MW. Cutaneous inflammatory cell infiltrate in chronic idiopathic urticaria: comparison of patients with and without anti-FcepsilonRI or anti-IgE autoantibodies. J Allergy Clin Immunol 1999;103:484-93.

31. Dubuske LM. Levocetirizine: The latest treatment option for allergic rhinitis and chronic idiopathic urticaria. Allergy Asthma Proc 2007;28:724-34.

32. Gimenez-Arnau A, Pujol RM, Ianosi S, Kaszuba A, Malbran A, Poop G, Donado E, Perez I, Izquierdo I, Arnaiz E; Rupatadine Urticaria Study Group. Rupatadine in the treatment of chronic idiopathic urticaria: a double-blind, randomized, placebo-controlled multicentre study. Allergy 2007;62:539-46.

33. Finn AF Jr, Kaplan AP, Fretwell R, Qu R, Long J. A double-blind, placebo-controlled trial of fexofenadine $\mathrm{HCl}$ in the treatment of chronic idiopathic urticaria. J Allergy Clin Immunol 1999;104:1071-8.

34. Di Lorenzo G, Pacor ML, Mansueto P, Esposito Pellitteri M, Lo Bianco C, Ditta V, Martinelli N, Rini GB. Randomized placebo-controlled trial comparing desloratadine and montelukast in monotherapy and desloratadine plus montelukast in combined therapy for chronic idiopathic urticaria. J Allergy Clin Immunol 2004;114: 619-25.

35. Ring J, Hein R, Gauger A, Bronsky E, Miller B. Once-daily desloratadine improves the signs and symptoms of chronic idiopathic urticaria: a randomized, double-blind, placebo-controlled study. Int J Dermatol 2001;40:72-6.

36. Siebenhaar F, Degener F, Zuberbier T, Martus P, Maurer M. Highdose desloratadine decreases wheal volume and improves cold provocation thresholds compared with standard-dose treatment in patients with acquired cold urticaria: a randomized, placebo-controlled, crossover study. J Allergy Clin Immunol 2009;123:672-9.

37. Wanderer AA, St Pierre JP, Ellis EF. Primary acquired cold urticaria. Double-blind comparative study of treatment with cyproheptadine, chlorpheniramine, and placebo. Arch Dermatol 1977;113:1375-7.

38. Sigler RW, Evans R 3rd, Horakova Z, Ottesen E, Kaplan AP. The role of cyproheptadine in the treatment of cold urticaria. J Allergy Clin
Immunol 1980;65:309-12.

39. Staevska M, Popov TA, Kralimarkova T, Lazarova C, Kraeva S, Popova D, Church DS, Dimitrov V, Church MK. The effectiveness of levocetirizine and desloratadine in up to 4 times conventional doses in difficult-to-treat urticaria. J Allergy Clin Immunol 2010;125:67682.

40. Kaplan AP. Clinical practice. Chronic urticaria and angioedema. N Engl J Med 2002;346:175-9.

41. Kaplan AP. What the first 10,000 patients with chronic urticaria have taught me: a personal journey. J Allergy Clin Immunol 2009; 123:713-7.

42. Simons FE. Advances in H1-antihistamines. N Engl J Med 2004; 351:2203-17.

43. Church MK, Maurer M, Simons FE, Bindslev-Jensen C, van Cauwenberge P, Bousquet J, Holgate ST, Zuberbier T; Global Allergy and Asthma European Network. Risk of first-generation H(1)-antihistamines: a GA(2)LEN position paper. Allergy 2010;65:459-66.

44. Kaplan AP, Joseph K, Maykut RJ, Geba GP, Zeldin RK. Treatment of chronic autoimmune urticaria with omalizumab. J Allergy Clin Immunol 2008;122:569-73.

45. Saini S, Rosen KE, Hsieh HJ, Wong DA, Conner E, Kaplan A, Spector S, Maurer M. A randomized, placebo-controlled, dose-ranging study of single-dose omalizumab in patients with H1-antihistamine-refractory chronic idiopathic urticaria. J Allergy Clin Immunol 2011;128:567-73.e1.

46. Spector SL, Tan RA. Effect of omalizumab on patients with chronic urticaria. Ann Allergy Asthma Immunol 2007;99:190-3.

47. Groffik A, Mitzel-Kaoukhov H, Magerl M, Maurer M, Staubach P. Omalizumab--an effective and safe treatment of therapy-resistant chronic spontaneous urticaria. Allergy 2011;66:303-5.

48. Maurer M, Altrichter S, Bieber T, Biedermann T, Bräutigam M, Seyfried S, Brehler R, Grabbe J, Hunzelmann N, Jakob T, Jung A, Kleine-Tebbe J, Mempel M, Meurer M, Reich K, Ruëff F, Schäkel K, Sengupta K, Sieder C, Simon JC, Wedi B, Zuberbier T, Mahler V, Staubach P. Efficacy and safety of omalizumab in patients with chronic urticaria who exhibit IgE against thyroperoxidase. J Allergy Clin Immunol 2011;128:202-9.e5.

49. Romano C, Sellitto A, De Fanis U, Esposito G, Arbo P, Giunta R, Lucivero G. Maintenance of remission with low-dose omalizumab in long-lasting, refractory chronic urticaria. Ann Allergy Asthma Immunol 2010;104:95-7.

50. Ferrer M, Gamboa P, Sanz ML, Goikoetxea MJ, Cabrera-Freitag P, Javaloyes G, Berroa F, Kaplan AP. Omalizumab is effective in nonautoimmune urticaria. J Allergy Clin Immunol 2011;127:1300-2.

51. Grattan CE, O'Donnell BF, Francis DM, Niimi N, Barlow RJ, Seed PT, Kobza Black A, Greaves MW. Randomized double-blind study of cyclosporin in chronic 'idiopathic' urticaria. Br J Dermatol 2000; 143:365-72.

52. Toubi E, Blant A, Kessel A, Golan TD. Low-dose cyclosporin A in the treatment of severe chronic idiopathic urticaria. Allergy 1997; 52:312-6.

53. Graudal N, Jürgens G. Similar effects of disease-modifying antirheumatic drugs, glucocorticoids, and biologic agents on radiographic progression in rheumatoid arthritis: meta-analysis of 70 randomized placebo-controlled or drug-controlled studies, including 112 comparisons. Arthritis Rheum 2010;62:2852-63.

54. McGirt LY, Vasagar K, Gober LM, Saini SS, Beck LA. Successful treatment of recalcitrant chronic idiopathic urticaria with sulfasalazine. Arch Dermatol 2006;142:1337-42. 